\title{
Investigation on the Use of Demolished Concrete and Glass in Concrete
}

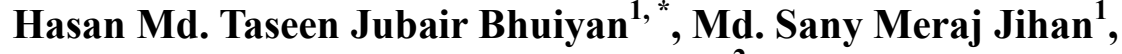 \\ Abdullah Md. Sarwaruddin Chowdhury ${ }^{2}$ \\ ${ }^{1}$ Department of Civil Engineering, Faculty of Civil Engineering, Rajshahi University of Engineering \& Technology (RUET), Rajshahi, \\ Bangladesh \\ ${ }^{2}$ Department of Applied Chemistry \& Chemical Engineering, Faculty of Engineering and Technology, University of Dhaka, Dhaka, \\ Bangladesh
}

\section{Email address:}

taseenjubair@gmail.com (H. Md. T. J. Bhuiyan), mdsanymeraj@gmail.com (Md. S. M. Jihan), profdrsarwar@gmail.com (A. Md. S. Chowdhury)

${ }^{*}$ Corresponding author

\section{To cite this article:}

Hasan Md. Taseen Jubair Bhuiyan, Md. Sany Meraj Jihan, Abdullah Md. Sarwaruddin Chowdhury. Investigation on the Use of Demolished Concrete and Glass in Concrete. Landscape Architecture and Regional Planning. Vol. 4, No. 4, 2019, pp. 81-86.

doi: 10.11648/j.larp.20190404.13

Received: October 18, 2019; Accepted: December 17, 2019; Published: December 27, 2019

\begin{abstract}
The problem of waste generation has rapidly become a serious issue of concern for many scholars. This study takes the problem of waste that is generated from construction fields, such as demolished concrete, glass and aims to reuse the construction and demolition debris for use as aggregates in construction purpose. Study involving reuse of demolition waste like demolished concrete, glass as partial replacement of coarse and fine aggregate up to $20 \%$ was performed before. But in those studies, either coarse aggregate is replaced with demolition waste or fine aggregate was replaced with glass. This study attempts to fully replace coarse aggregate with demolished concrete and crushed glass as partial replacement of fine aggregate to a content of 20, 25 and $30 \%$, respectively. The main findings of this investigation revealed that using glass in lieu of sand at $30 \%$ replacement as fine aggregate gives maximum compressive strength which is significantly greater than M35 (35 MPa) grade concrete and nearing M40 (40 MPa) to M45 (45MPa) grade concrete, which indicates the suitability of use in various constructions. It also revealed that with increasing quantity of glass the corresponding strength increase doesn't occur linearly, but the rate of increase gradually slows down with increasing of the amount of glass in the concrete samples.
\end{abstract}

Keywords: Demolished Concrete, Glass, Sand, Concrete, Compressive Strength

\section{Introduction}

As the number of constructions of various concrete structures is increasing, so is the quantity of demolition waste. Demolition waste includes concrete glass, metal and other wastes. These demolished concrete and glass wastes may still be used as an alternate raw material for various kinds of construction. This study attempts to cover the viability of use as such an alternative source of raw material for construction of concrete structures. Recycling concrete as aggregate offers a solution to the problems encountered with the quarrying of natural aggregates and the disposal of old concrete. As these substitutes require extensive studies about their effect on the properties of concrete, a number of Research studies were performed namely, Wilson (1993) studied the effect of the irregular surface of the crushed concrete properties of the concrete mixes [17]. The use of plastic materials and glass in a number of civil engineering applications has been investigated through a large number of research studies. These have been conducted to examine the possibility of using plastics and glass powder in various civil engineering projects in the construction field [18-20]. Sustainability of waste glass for use in road construction aggregate, asphalt paving, concrete aggregate, and many other applications were researched in the studies such as [18]. Ahmad Shayan $(1999,2002)$ studied the use of waste glass aggregates in concrete [20, 21]. The use recycled aggregates saves natural resources and dumping spaces, and helps to maintain a clean environment. The 
current study concentrates on these waste materials, especially glass waste and building construction waste to be used as substitutes for conventional materials in ordinary cement concrete (OPC) mixes. This will be demonstrated through experimental laboratory tests, using fine glass to substitute a certain percentage of fine aggregates (sand), whilst using crushed brick concrete to substitute a full percentage of course aggregates in OPC concrete. Here this investigation will cover the viability of use of concrete demolition as a full replacement for coarse aggregate and also the effectiveness of using glass as a partial replacement for sand as fine aggregate.

\section{Materials and Methods}

\subsection{Materials}

The construct materials used in this test are cement, sand, coarse aggregate and crushed glass power. Normal top water was used for soaking and curing purposes.

It is essential to know about the strength of cement, the physical properties of sand, coarse aggregates and glass powder.

To achieve the objective of present investigation, extensive and comprehensive experimental program has been planned. The entire investigation has classified into various phases of work for through and systematic approach.

In the first phase, the physical and material properties of sand, crushed glass powder, cement, sand and aggregate from demolished concrete were determined and recorded. The second phase of the phase was the casting and preparing of the mold. The third phase of the mold was curing the mold for 7 and 28 days for several sets of cylindrical concrete samples. The fourth and final phase was the testing of the mold with the Universal Testing Machine of capacity.

All the tests and investigations were conducted in the Strength of material laboratory of Rajshahi University of Engineering \& Technology (RUET), Rajshahi.

\subsection{Experimental Investigation}

i. The concrete mix was prepared by talking the proportion of cement, fine aggregate and coarse aggregate in a ratio of $1: 1.5: 3$ respectively.

ii. The water cement ratio (w/c) was assumed to be $1: 4$ iii. 9 cylindrical molds each of 3-inch diameter and 6-inch height and every three having the same percentage of glass powder were to be prepared and cured for 28 days.

\subsection{Preparation of Specimen}

i. Initially the waste glass was crushed into glass powder by hammer up to a size finer than $0.85 \mathrm{~mm}$.

ii. Sand, glass and khoa or coarse aggregate were screened by sieve according to requirements.

iii. Concrete constituents (cement, sand, glass powder and coarse aggregate) were measured separately by weight according to the required proportion.

iv. The percentage of replacing fine aggregates with glass varied from $20 \%$ to $30 \%$ each applied in an individual concrete mix. The proportion of the mix was shown in the table. The recycled aggregates were produced by crushing the old concrete cubes and cylinders used and discarded from previous laboratory tests.

v. The crushed concrete was then screened using the sieve analysis method.

vi. The quantity of fine particles used was measured for each specimen.

\section{Results and Discussion}

\subsection{Figure (Gradation Curve of Glass)}

Figure 1 below shows the gradation curve of the glass particles used in the test. The variation of the size of glass particles in the concrete mix can be identified from this curve.

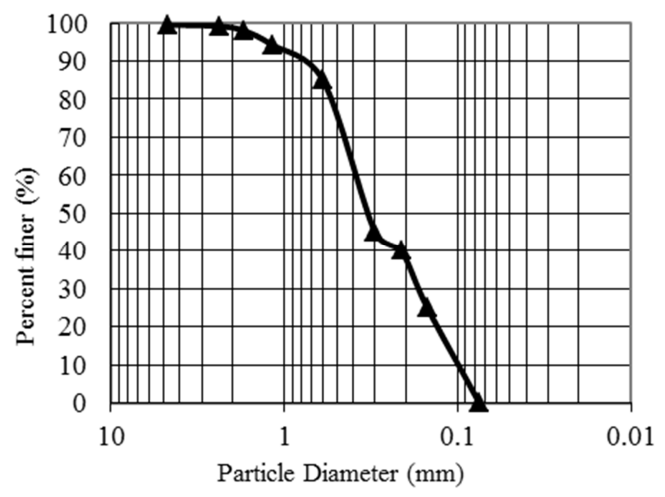

Figure 1. Gradation Curve (Glass).

\subsection{Table (Amount of Materials Used in Each Sample)}

Table 1. Proportion of Coarse And Fine Aggregates In Concrete Mix.

\begin{tabular}{llll}
\hline Specimen no & $\mathbf{9 . 5 1} \mathbf{m m}(\mathbf{1 0} \%$ of total retained) in $\mathbf{~ K g}$ & $\mathbf{1 2 . 7} \mathbf{m m}(\mathbf{3 5 \%}$ of total retained) in $\mathbf{~ K g}$ & $\mathbf{1 9 m m}(\mathbf{5 5 \%}$ of total retained) in $\mathbf{~ K g}$ \\
\hline 1 & 0.13 & 0.46 & 0.72 \\
2 & 0.13 & 0.46 & 0.72 \\
3 & 0.13 & 0.46 & 0.72 \\
\hline
\end{tabular}

Table 2. Full Replacement of Aggregate (1.3 Kg) Per Specimen.

\begin{tabular}{llll}
\hline Percentage of glass $\%$ & Sand $(\mathbf{K g})$ & Glass $(\mathbf{k g})$ & Coarse aggregate $($ Kg) \\
\hline 20 & 0.57 & 0.23 & 1.3 \\
25 & 0.55 & 0.29 & 1.3 \\
30 & 0.51 & 0.35 & 1.3 \\
\hline
\end{tabular}


The percentage of sand, glass and coarse aggregate used in the concrete samples are given in the table 1 above. The aggregate gives structure to the concrete. Which allows it to form a solid rigid uniform block.
Table 2 above shows the variation of aggregate sizes and their content in each concrete sample. Variation of both coarse and fine aggregate sizes allows for the elimination of voids in the concrete block samples.

Table 3. Amount of Materials Used Per Specimen.

\begin{tabular}{|c|c|c|c|c|c|c|c|c|c|c|c|}
\hline \multirow{2}{*}{ SL no } & \multirow[t]{2}{*}{ Cement (Kg) } & \multicolumn{3}{|c|}{ Sand $(\mathrm{Kg})$} & \multicolumn{3}{|c|}{ Glass (Kg) } & \multicolumn{3}{|c|}{ Aggregate (Kg) } & \multirow{2}{*}{$\begin{array}{l}\text { Water }(\mathrm{Kg}) \\
0.4 \times 0.4\end{array}$} \\
\hline & & $0.6 \mathrm{~mm}$ & $0.3 \mathrm{~mm}$ & $0.15 \mathrm{~mm}$ & $0.6 \mathrm{~mm}$ & $0.3 \mathrm{~mm}$ & $0.15 \mathrm{~mm}$ & $19 \mathrm{~mm}$ & $12.7 \mathrm{~mm}$ & $9.51 \mathrm{~mm}$ & \\
\hline 1 & 0.41 & 0.1995 & 0.285 & 0.09 & 0.069 & 0.1035 & 0.0575 & 0.72 & 0.46 & 0.13 & 0.164 \\
\hline 2 & 0.41 & 0.1995 & 0.285 & 0.09 & 0.069 & 0.1035 & 0.0575 & 0.73 & 0.46 & 0.13 & 0.164 \\
\hline 3 & 0.41 & 0.1925 & 0.275 & 0.0825 & 0.087 & 0.1305 & 0.0725 & 0.73 & 0.46 & 0.13 & 0.164 \\
\hline 4 & 0.41 & 0.1925 & 0.275 & 0.0825 & 0.087 & 0.1305 & 0.0725 & 0.73 & 0.46 & 0.13 & 0.164 \\
\hline 5 & 0.41 & 0.1785 & 0.255 & 0.0765 & 0.105 & 0.1575 & 0.0875 & 0.73 & 0.46 & 0.13 & 0.164 \\
\hline 6 & 0.41 & 0.1785 & 0.255 & 0.0765 & 0.105 & 0.1575 & 0.0875 & 0.73 & 0.46 & 0.13 & 0.164 \\
\hline Total & 2.46 & 1.41 & 1.63 & 0.498 & 0.522 & 0.783 & 0.435 & 4.38 & 2.76 & 0.78 & 0.984 \\
\hline
\end{tabular}

The total amount of glass, cement, aggregate, sand and water used per specimen is given in table 3 . It also shows the type of sieving used to get the desired materials for the test.

The data from table 3 gives optimum amount of optimum amount of material for each concrete mix. In practice the water content might be varied slightly to increase workability and improve the uniformity of the mix. Which helps in the improvement of the strength of the concrete samples.

\subsection{Table (Compression Test Results)}

Compression testing of the cylindrical specimens was carried out in Universal Testing Machine of capacity $3000 \mathrm{kN}$. The cylinders were weighed and load was applied without any shock. A set of three concrete cylinders were tested for each of the mix for their compressive strengths at 28 days of curing. The ultimate load at which specimen failed was noted down for each specimen. The ratio of the crushing loads to the surface area of the cylinders gives the ultimate strength of the corresponding concrete cylinder.

Tables 4 and 5 represent that the compressive strength of all concrete mixes increased with the increase of curing age. The load carrying capacity increases with increase in curing time.

Table 4. Compressive Strength of Specimen For 7 Days of Curing.

\begin{tabular}{lllll}
\hline Glass content & Specimen no & Load at failure (kN) & Coarse aggregate (Kg) & Ultimate Compressive strength (MPa) \\
\hline $20 \%$ & 1 & 105.2 & 23.15 & $20 \%$ \\
$25 \%$ & 2 & 114.4 & 25.22 & $25 \%$ \\
$30 \%$ & 3 & 125.6 & 27.69 & $30 \%$ \\
\hline
\end{tabular}

Table 5. Compressive Strength of Specimen For 28 Days of Curing.

\begin{tabular}{llll}
\hline Glass content & Specimen no & Load at failure (kN) & Ultimate Compressive strength (MPa) \\
\hline \multirow{2}{*}{$20 \%$} & 1 & 159.8 & 35.25 \\
& 2 & 155.6 & 34.31 \\
& 3 & 162.4 & 35.61 \\
$25 \%$ & 4 & 172.3 & 37.98 \\
& 5 & 166.2 & 36.64 \\
& 6 & 178.3 & 39.09 \\
$30 \%$ & 7 & 179.1 & 39.48 \\
& 8 & 181.5 & 40.01 \\
\hline
\end{tabular}

\subsection{Figure (Compressive Strength Charts for 7-day Curing)}

Figure 2 shows the variation of compressive strength for 7- day curing. It is observed that, the higher the percentage of glass powder in concrete, the higher the compressive strength.

The load vs time graph obtained for compression test for 7-day curing is shown in the figure 3. These graphs give the Ultimate compressive strength of the cylindrical specimens. 


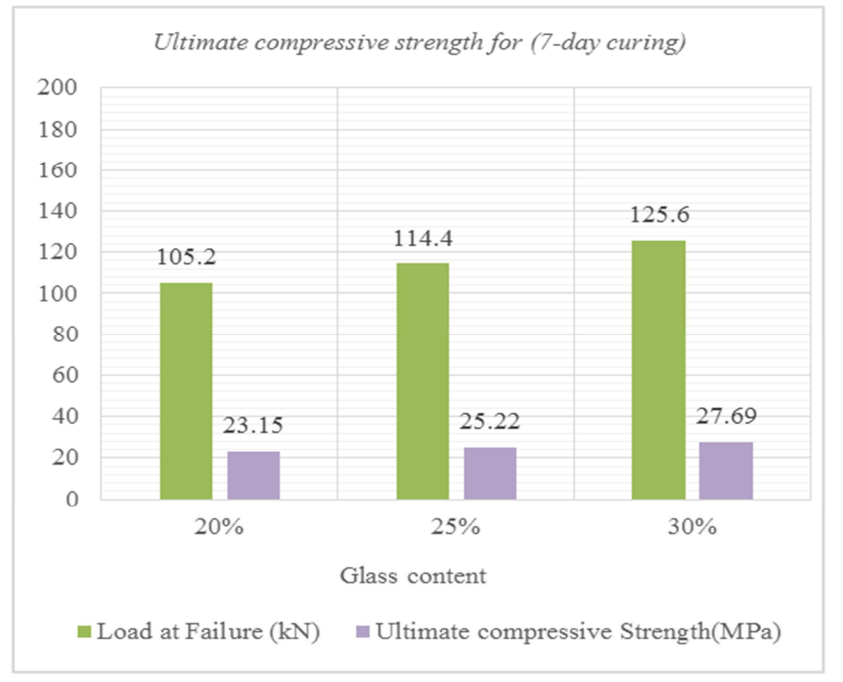

Figure 2. Ultimate compressive strength for (7-day curing).

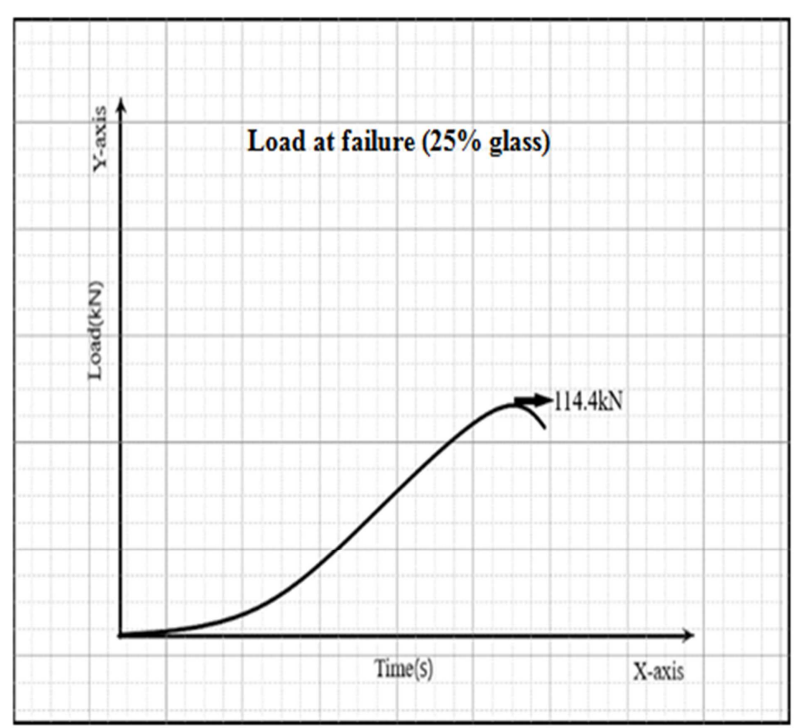

Figure 3. Load vs time curve from Universal testing machine (7-day curing).

\subsection{Figure (Compressive Strength Charts for 28-day Curing)}

Figure 4 shows the variation of ultimate compressive strength of the concrete specimens containing $20 \%$ glass particles.

Figure 5 shows the maximum load at failure for the specimen with $25 \%$ glass particle mixed with sand.

Figure 6 gives the maximum load at failure for the specimen with $30 \%$ glass particle mixed with sand.

It is evident

Figure 7 shows the load vs time is obtained from the compression test machine. The specimen used for this test was cured for 28 days. The point of failure is determined by the point at which the curve starts to descend instead of ascending.

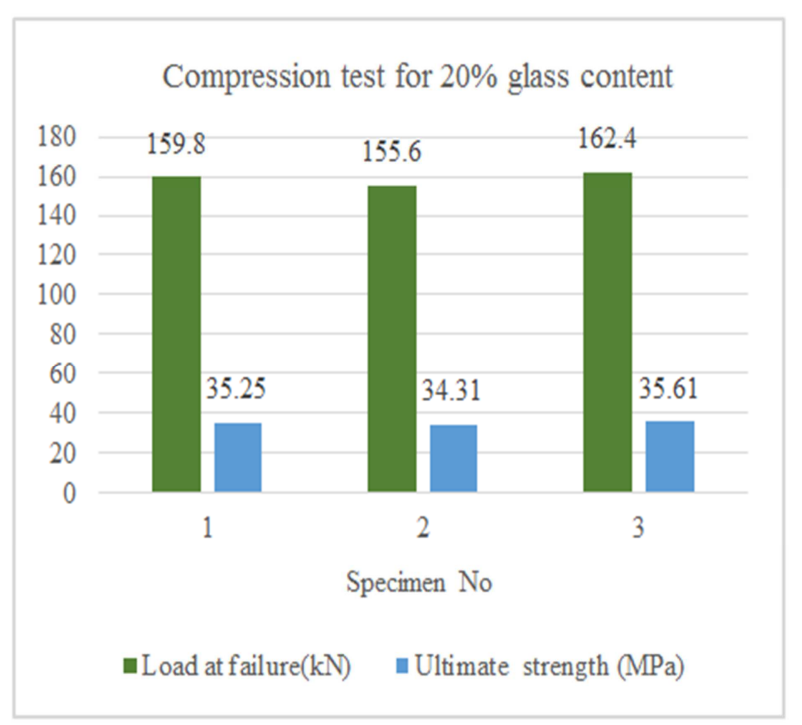

Figure 4. Ultimate compressive strength for 28-day curing (20\% glass).

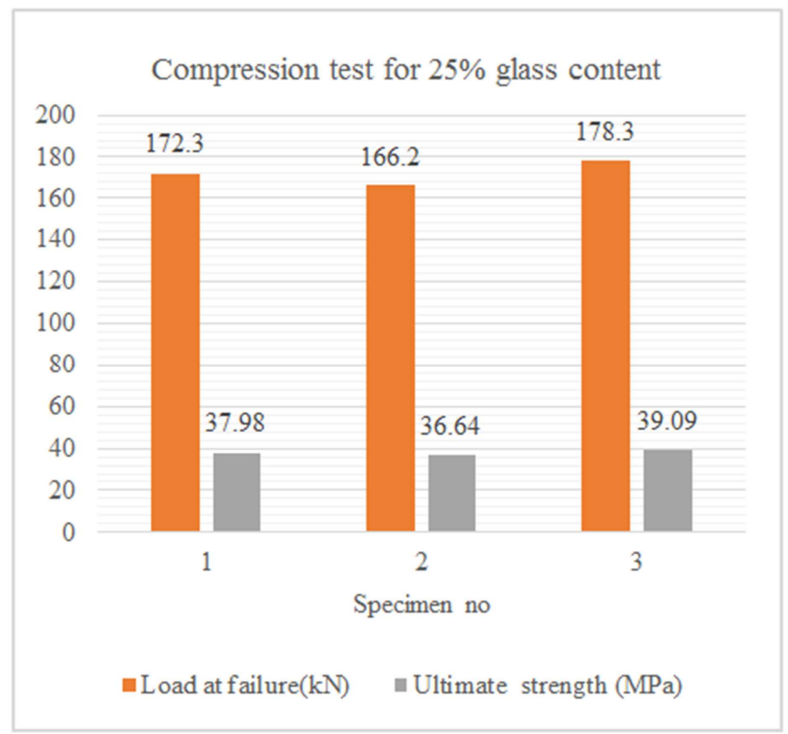

Figure 5. Ultimate compressive strength for 28-day curing (25\% glass).

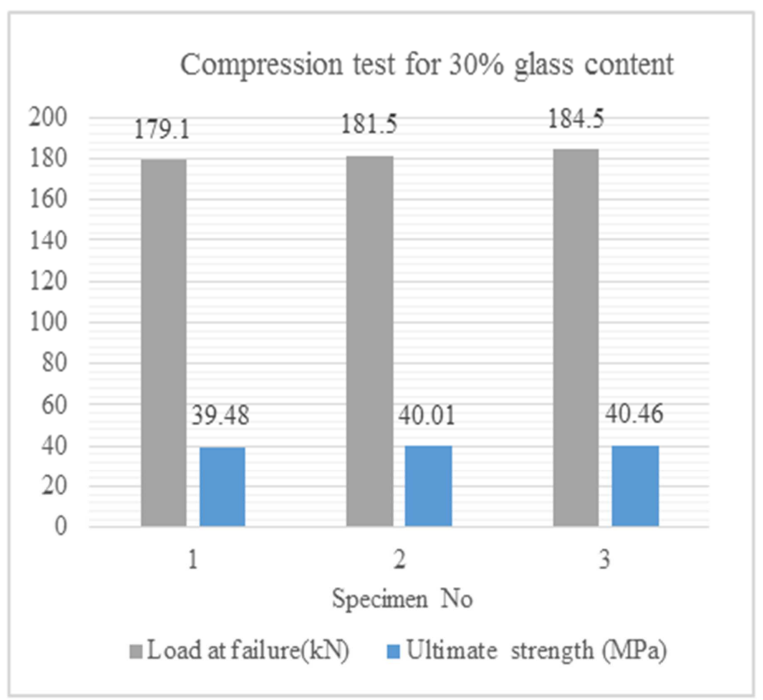

Figure 6. Ultimate compressive strength for 28-day curing. 


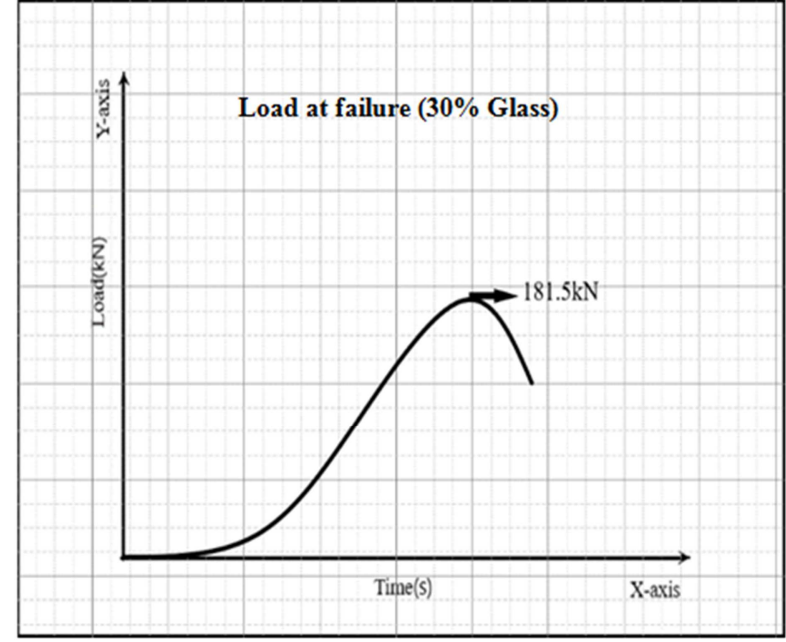

Figure 7. Load vs time curve from compression test machine (28-day curing).

The graph in figure 9 shows the variation of ultimate as fine aggregate for 28-day curing. It is determined from the graph data that the ultimate compressive strength of the concrete specimen increases significantly as the percentage of glass is increased in the concrete mix. It also seen that the rate of increase in compressive strength while going from $20 \%$ to $25 \%$ glass content is greater than that of $25 \%$ to $30 \%$ glass content. It seems that the rate of compressive strength gain starts to slow down steadily after $25 \%$ sand replacement with glass.

\subsection{Figure (Ultimate Compressive Strength Curves)}

The graph in figure 8 shows the variation of ultimate compressive strength with the increase of percentage of glass as fine aggregate for 7-day curing. It is evident from the graph data that the ultimate compressive strength of the concrete specimen increases steadily as the percentage of glass is increased in the concrete mix. strength due to addition of glass is more apparent in specimen with 28-day curing time.

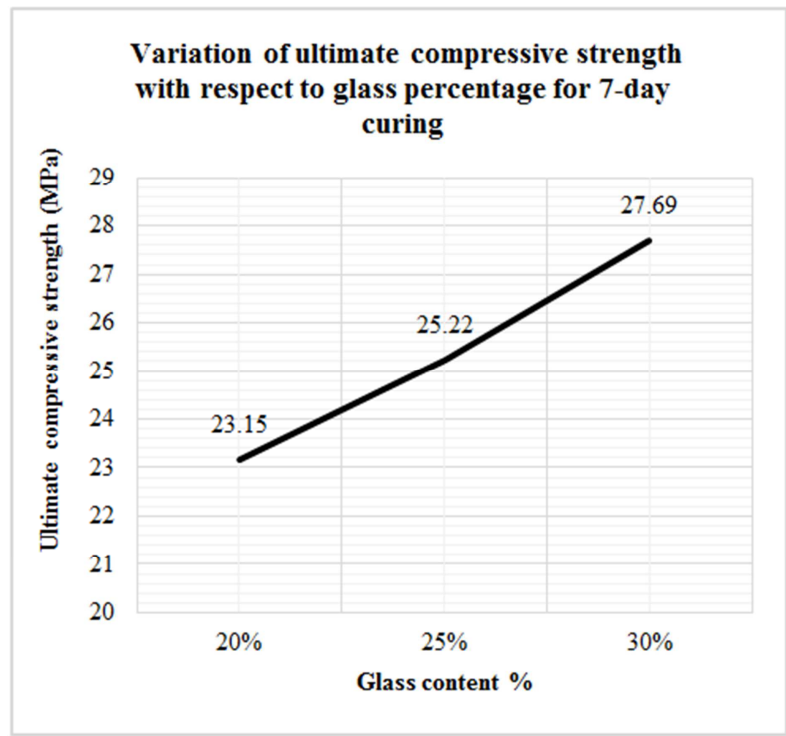

Figure 8. Variation of ultimate compressive strength with respect to glass percentage for 7-day curing.

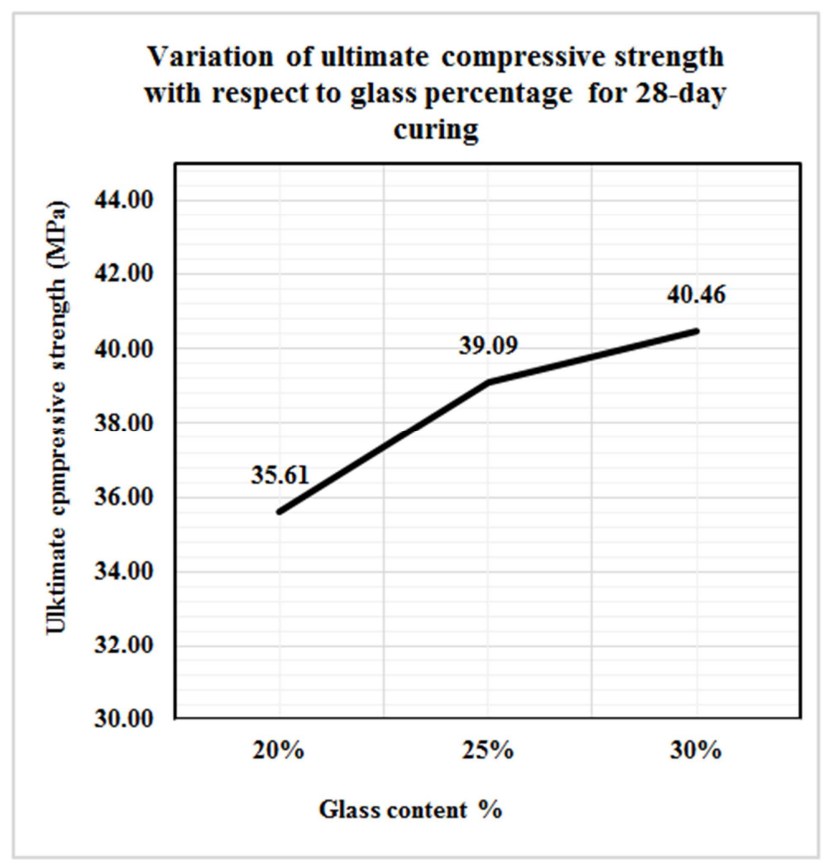

Figure 9. Variation of ultimate compressive strength with respect to glass percentage for 28-day curing.

\section{Conclusion}

The experiment carried out primarily designed to primarily designed to provide an indication of relative advantages and disadvantages of the use of a number of construction and demolition wastes. This would provide as an overview of the probable reuse of construction and demolition waste materials in the construction of rigid pavements.

Based on the test results and physical observations, the following conclusions can be drawn:

With the increase of crushed glass powder in concrete mix, the compressive strength of concrete increases.

The Ultimate compressive strength values are greater than M35 grade concrete (35 MPa) and 30\% replacement of sand with glass nears M40 grade (40 MPa) concrete.

The rate of increase of compressive strength starts to slow down after reaching a glass content of $25 \%$. Waste concrete aggregate and glass fine aggregate is suitable for use in concrete.

\section{Recommendations}

The conclusion statements that can be made for future research in this field of similar specimen as used in the scope of this study are equating the concrete strength.

The increase of the surface area of the recycled crushed concrete, due to its irregular shape, necessitates an increase of cement and water.

The strength of concrete mixes was improved by partial replacement of fine aggregates with fine crushed glass aggregates, but the high alkali content of such aggregates would affect the long-term durability and strength, which will need long term investigation. 
Using window glass may affect the long-term durability due to Alkali-silica reaction (ASR). Using glass from green bottles may be a topic for future study as the existence of chromium oxide in green bottles may mitigate Alkali-silica reaction (ASR).

\section{Acknowledgements}

Special thanks are due to the scientific staff of Rajshahi University of Engineering \& Technology (RUET) \& Dhaka University (DU) for providing the necessary cooperation and support in this experiment.

\section{References}

[1] Omahony, M. M. (1997). An analysis of the shear strength of recycled aggregates. Materials and Structures, 30 (10), 599606.

[2] Taesoon Park. (2003). Application of Construction and Building Debris as Base and Subbase Materials in Rigid Pavement. Journal of Transportation Engineering. 129. 558-563.

[3] Jha, Kumar \& Rao, Akash \& Misra, Sudhir. (2007). Use of aggregates from recycled construction and demolition waste in concrete. Resources Conservation and Recycling.

[4] Malek K Batayneh, \& Iqbal Marie \& Ibrahim Asi. (2007). Use of selected waste materials in concrete mixes. Waste management (New York, N. Y). 27 1872-1876.

[5] Topcu, I. B., Boğa, A. R., \& Bilir, T. (2008). Alkali-silica reactions of mortars produced by using waste glass as fine aggregate and admixtures such as fly ash and $\mathrm{Li} 2 \mathrm{CO} 3$. Waste management, 28 5, 878-84.

[6] Vancura, Mary \& Khazanovich, Lev \& Tompkins, Derek. (2009). Reappraisal of Recycled Concrete Aggregate as Coarse Aggregate in Concretes for Rigid Pavements. Transportation Research Record. 2113. 149-155.

[7] Idir, R., Cyr, M. and Tagnit-Hamou, A. (2010) Use of Fine Glass as ASR Inhibitor in Glass Aggregate Mortars. Construction and Building Materials, 24, 1309-1312.

[8] Mageswari, M., \&Vidivelli, D. B. (2010). The Use of Sheet Glass Powder as Fine Aggregate Replacement in Concrete. The Open Civil Engineering Journal, 4 (1), 65-71.
[9] Xuan, D. X., Houben, L. J. M., Molenaar, A. A. A., \& Shui, Z. H. (2011). Mixture optimization of cement treated demolition waste with recycled masonry and concrete. Materials and Structures, 45 (1-2), 143-151.

[10] Ling, T.-C., \& Poon, C.-S. (2012). A comparative study on the feasible use of recycled beverage and CRT funnel glass as fine aggregate in cement mortar. Journal of Cleaner Production, 29-30, 46-52.

[11] Parbat, Dhananjay. (2013). REPLACEMENT OF NATURAL SAND IN CONCRETE BY WASTE PRODUCTS: A STATE OF ART. Journal of Environmental Research and Development. 7. 1651-1656.

[12] Monish, Mohd \& Srivastava, Vikas \& Agarwal, V \& Mehta, P \& Kumar, Rakesh. (2013). Demolished waste as coarse aggregate in concrete. Journal of Academia and Industrial Research. $19540-543$.

[13] Ulloa, Vivian \& Garcia Taengua, Emilio \& Pelufo, Maria \& Domingo, Alberto \& Serna, P. (2013). New Views on Effect of Recycled Aggregates on Concrete. Materials Journal 1106 687-696.

[14] Harvey, Brad, "Compressive Strength Relative to Sustainable Materials in Concrete" (2017). Honors Research. Projects. 538.

[15] Suganya, Suganya. (2014). Use of Glass Powder as Fine Aggregate in High Strength Concrete. 2.

[16] Halahla, Abdul samee \& Akhtar, Mohammad \& Almasri, Amin (2019). Utilization of Demolished Waste as Coarse Aggregate in Concrete. Civil Engineering Journal. 5. 540.

[17] Wilson, Alex, (1993). Cement and concrete environmental considerations. Environ. Build. News 2.

[18] Ablam Zidol, Monique Tognonvi \& A. Tagnit-Hamou. (2017). Effect of Glass Powder on Concrete Sustainability. New Journal of Glass and Ceramics. 07. 34-47.

[19] Chanbane, B., Sholar, G. A., Musselman, J. A., Page, G. C., 1999. Ten-year performance evaluation of asphalt-rubber surface mixes. Transportation Research Record No. 1681, Transportation Research, Washington, DC, pp. 10-18.

[20] Shayan, A., Xu, A, 1999. Utilization of glass as a pozzolanic material in concrete ARRB TR Internal Report RC91132.

[21] Shayan, A., 2002. Value-added utilization of waste glass in concrete. In IABSE Symposium, Melbourne. 